\title{
PROPOSTA DE ADEQUAÇÕES DAS INSTALAÇÕES DE PROTEÇÃO E COMBATE A INCÊNDIO DE UMA EDIFICAÇÃO INDUSTRIAL EM MANAUS-AM
}

\section{ARTIGO ORIGINAL}

OLIVEIRA, Flávio Marcio da Conceição ${ }^{1}$

BARBOSA, Jessika Melinda dos Santos ${ }^{2}$

CUNHA, Glaucivan Barroso da ${ }^{3}$

JUNIOR, Antonio Oscar de Goes ${ }^{4}$

PEREIRA, Elisângela Rosas ${ }^{5}$

OLIVEIRA, Flávio Marcio da Conceição. Et al. Proposta de Adequações das Instalações de Proteção e Combate a Incêndio de uma Edificação Industrial em Manaus-Am. Revista Científica Multidisciplinar Núcleo do Conhecimento. Ano 04, Ed. 10, Vol. 13, pp. 92-110. Outubro de 2019. ISSN: 2448-0959, Link de acesso: https://www.nucleodoconhecimento.com.br/engenharia-civil/combate-aincendio

\section{RESUMO}

O presente estudo tem por objetivo propor um Plano de Segurança Contra Incêndio e Pânico - PSCIP em um edifício industrial no município de Manaus, este projeto visa a

\footnotetext{
${ }^{1}$ Graduando em Engenharia Civil.

2 Graduanda em Engenharia Civil.

${ }^{3}$ Graduada em Engenharia Elétrica e Mestre em Engenharia Industrial.

${ }^{4}$ Graduado em Engenharia Civil.

${ }^{5}$ Graduando em Engenharia Civil e Pós graduada em Gerenciamento de obras e empreendimento na construção civil.
} 
segurança e proteção contra incêndios devendo ser encarada como obrigação de proteger as vidas humanas e o patrimônio envolvido, garantindo a sinalização de rotas de fuga necessárias para evacuação da empresa em caso de sinistro, atendendo às exigências normativas e as Instruções Técnicas do Corpo de Bombeiros. Com base em pesquisa de campo e bibliográficas, pôde-se fazer o levantamento das áreas, que auxiliaram nas definições das etapas e elaboração do projeto de prevenção, fazendo alterações significativas no layout atual da edificação. Como resultado observou-se que as adequações ocorreram devido a ampliação no sistema de detecção e combate ao incêndio e de substituições de peças danificadas. Conclui-se que os problemas observados na visita in loco, em sua maioria são referentes a falta de manutenção dos equipamentos de segurança e da atualização da planta industrial da empresa. A edificação industrial em estudo necessita de adequação no plano de segurança e combate a incêndio de acordo com as exigências descritas em leis e normas técnicas vigentes.

Palavras-Chaves: edificações, incêndios, prevenção, segurança.

\section{INTRODUÇÃO}

Em todas as edificações a proteção contra incêndios deve ser projetada por profissionais devidamente habilitado, e os projetos devem estar de acordo com as Normas Técnicas, Leis, Portarias e Resoluções do Corpo de Bombeiros, a qual direciona a elaboração dos projetos de prevenção, a fim de garantir a sua plena funcionalidade e proteção contra incêndio.

"Segundo a Norma Regulamentadora, NR 23 - Proteção Contra incêndios do Ministério do Trabalho e Emprego, todos os empregadores devem adotar medidas de prevenção de incêndios, em conformidade com a legislação estadual e as normas técnicas aplicáveis" (BRASIL, 2011).

As edificações precisam ser projetadas de acordo com o uso e riscos que estarão expostas, e sempre está atento a segurança de seus colaboradores. Mas nem sempre foi assim, foi preciso acontecer grandes tragédias no decorrer dos tempos, para alterar 
o código de segurança, tornando-se mais rígido as normas aplicáveis contra incêndios.

O objetivo deste trabalho consiste propor um projeto de Plano de Segurança Contra Incêndio e Pânico - PSCIP em um edifício industrial em Manaus, atualizando o projeto industrial da empresa e até mesmo se adequar as exigências legais de prevenção de incêndio em suas instalações, para que se tenha um ambiente seguro. Com base nas visitas in loco, observou-se que em alguns pontos necessitavam de melhorias nas infraestruturas dos sistemas de detecção e alarme de incêndio no prédio industrial, que deve ter ocorrido pela falta de manutenção dos equipamentos pelos responsáveis. Com base no estudo será proposto algumas melhorias para a prevenção e controle de riscos, a fim de garantir sua plena funcionalidade em suas instalações.

\section{FUNDAMENTAÇÃO TEÓRICA}

Segundo Brentano (2010, P.6), "o fogo é uma reação química, que ocorre com a oxidação rápida do material combustível com o ar, provocada por uma fonte de calor, que gera chama, libera calor, emite fumaça, gases e outros resíduos".

Dreher (2004), conceitua o fogo como, a consequência de um a reação química denominada combustão que libera luz e calor. Para que haja combustão deverão estar presentes quatro elementos: combustível, calor, oxigênio e reação em cadeia.

De acordo com Pereira e Junior (2010), fogo é uma energia útil ao bem-estar da humanidade, que deve ser controlada, uma vez que essa imensa energia pode causar, quando descontrolada, danos irreparáveis.

Os autores descrevem a reação do fogo e suas consequências, em virtude aos cuidados que as indústrias devem ter em manuseá-los. Assim os profissionais que projetam devem estar atentos aos cuidados com os requisitos básicos de desempenho do projeto e atualização da planta arquitetônica com o layout atual da edificação. 


\subsection{CLASSES DE INCÊNDIOS E MÉTODO DE EXTINÇÃO}

Para Camillo Junior (2013), "existem quatro madeiras de se acabar com algum dos componentes do fogo. A extinção por retirada de material, abafamento, resfriamento, ou extinção química".

"Resfriamento é o método utilizado para diminuir a temperatura do material em combustão, visando retirar o calor produzido do fogo, até a temperatura abaixo do ponto de combustão ou de ignição [...]" (PEREIRA e POPOVIC, 2007, p.35).

De acordo com Brentano (2007), os incêndios são classificados, de acordo com o material combustível, em cinco classes: A, B, C, D e K, conforme figura 01.

Figura 01 - Classe de fogos.
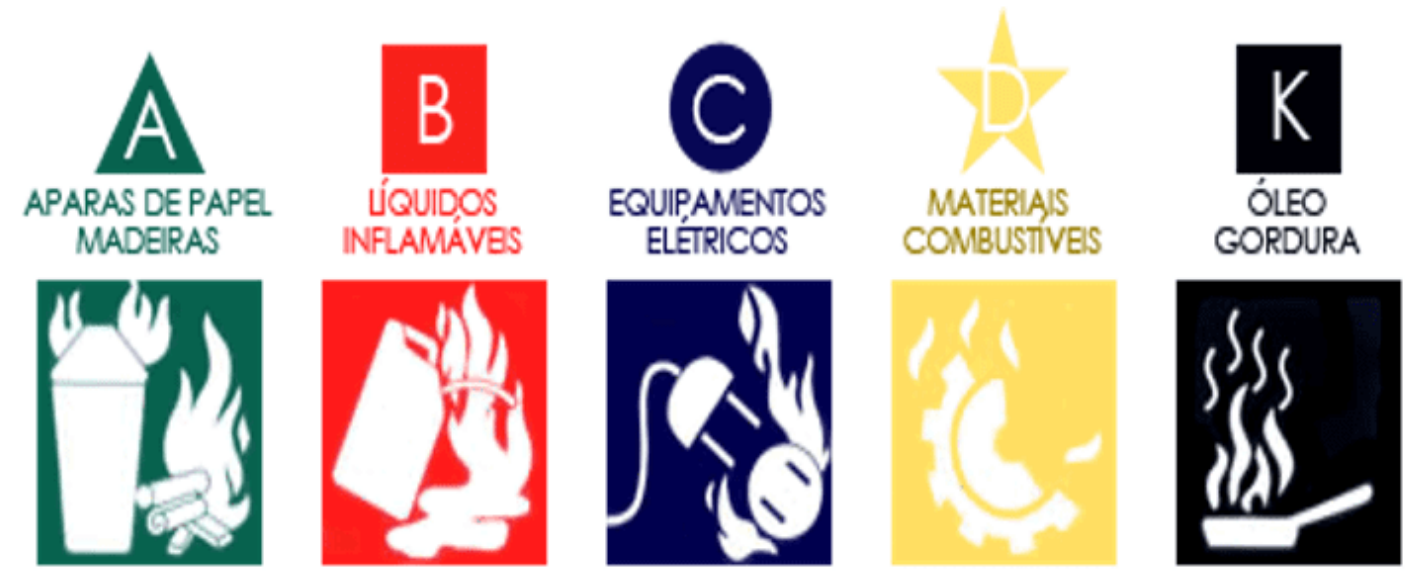

Fonte: EXTINGUE INCÊNDIO, 2019.

- Classe A - Fogo em materiais de fácil combustão (madeira, pano, borracha, plástico, etc.). Característica de queimar em função do seu volume, deixando partes cinzas, ou resíduos fibrosos.

- Classe B - Fogo em líquidos inflamáveis ou gases. Queima apenas em superfície e não deixa resíduos.

- Classe C - Fogo em equipamentos elétricos (motores, aparelhos, televisores etc.). Poderá se tornar de classe A ou B se o combustível for desenergizado. 
- Classe D - Fogo em materiais que reagem com água, e de altas temperaturas, como Magnésio, Alumínio entre outros.

- Classe K: São os fogos em óleos e gorduras em cozinhas.

Para Mitidieri et al. (2008), a severidade de um incêndio está relacionada com os efeitos causados pela ação das chamas e calor sobre os materiais que compõem as edificações, levando em consideração o tipo de revestimento e acabamento.

Para cada classe de incêndios são utilizados um tipo de extintores, que age por resfriamento e quebrando a reação da combustão.

- Extintor de água (H2O): É indicado para combate de fogo classe A.

- Extintor de espuma: É indicado para combate ao fogo classe B e pode ser usado para classe $\mathrm{A}$.

- Extintor de gás carbônico (CO2): Recomendado para combate de fogo classe B e C.

- Extintor de pó químico: Possui vários tipos de composição em grupos $B C, A B C$ e D.

Esse tipo de classificação é muito importante, pois ajuda no controle da prevenção e os riscos que o incêndio poderá causar nas edificações, além de acidentes no trabalho.

\subsection{CAUSAS DE INCÊNDIO}

Segundo Pozzobon (2010), quando se estudam as causas de um incêndio, procurase saber como, porque e onde iniciou o processo de combustão, se a sua origem é proveniente da ação direta do homem ou não. Pode-se classificar as causas de um incêndio como:

- Causas humanas (culposas e criminosas): A causa humana culposa é causada pela ação direta do homem por negligência, imprudência ou imperícia. 
- Causas naturais: Ocorrem pelos chamados fenômenos naturais, tais como raios, descargas atmosféricas, terremotos, erupções vulcânicas e desabamentos;

- Causas acidentais (elétricas, mecânicas e químicas): Ocorrem devido as falhas ocasionais.

- Causas industriais: o risco de incêndios industriais vem aumentando devido à utilização de novos materiais e projetos de edificações, além do grande consumo de energia para atender a demanda da mão de obra.

Esse tipo de falhas acontece nos projetos e execuções das instalações, negligenciando a ocupação da edificação. Tendo sua propagação muitas das vezes imprevisível ignorando as exigências quanto à segurança contra incêndio.

\subsection{PREVENÇÃO CONTRA INCÊNDIOS}

De acordo com Ono (2007, p. 99), "a área de segurança contra incêndio ganhou impulso no país, especificamente no estado de São Paulo, na metade da década de 1970, quando ocorreram dois incêndios de grandes proporções no edifício Andraus e no edifício Joelma".

Logo após esses acidentes o ministério do trabalho editou a Norma Regulamentadora 23 (NR-23) - Proteção Contra Incêndios, em 1978 fazendo uma restruturação na segurança do trabalho e novas regras de proteção.

Para Seito et al (2008), essas tragédias provocaram mudanças na legislação, nas corporações de bombeiros, nos institutos de pesquisa e foi iniciado um processo de formação de técnicos e pesquisadores preocupados com essa área de conhecimento.

Conforme Bonitese (2007, p. 3), "no estudo de segurança contra incêndio, torna-se iminente a necessidade de fusão entre medidas normativas e o processo de concepção do projeto arquitetônico, de maneira a potencializar o fator segurança nas edificações [...]". 
Esses incêndios causaram grande impacto, dando início ao processo de reformulação das medidas de segurança contra incêndios. Assim, foram surgindo normas e códigos na perspectiva de minimizar esses fatores de riscos.

\subsection{PROJETO DE SEGURANÇA CONTRA INCÊNDIO}

Segundo Seito et al (2008), o enfoque da engenharia de segurança contra incêndio deve considerar um conjunto muito abrangente de variáveis a serem analisadas, fornecendo, desta forma, uma solução mais abrangente e científica.

A medida de segurança em qualquer que seja o tipo de uso da edificação, podem ser de natureza preventiva e também protetiva.

As medidas de prevenção de incêndio são aquelas associadas ao elemento precaução contra o início do incêndio e se destinam, exclusivamente, a prevenir a ocorrência do início do incêndio, ou seja, controlar o risco de início de incêndio. As medidas de proteção contra incêndio são aquelas destinadas a proteger a vida humana e os bens materiais dos efeitos nocivos do incêndio que já se desenvolve no edifício. São necessárias ao sistema global de segurança contra incêndio, na proporção em que as medidas de prevenção venham a falhar, permitindo o surgimento do incêndio. Estas medidas compõem os seguintes elementos do sistema global: limitação do crescimento do incêndio; extinção inicial do incêndio; limitação de propagação do incêndio; precaução contra a propagação entre edifícios; evacuação segura do edifício; precaução contra o colapso estrutural; e rapidez, eficiência e segurança das operações de combate e resgate (BERTO, 1991).

Para ONO (2007, p. 98) afirma que:

A segurança contra incêndio, apesar de ser considerada um dos requisitos básicos de desempenho no projeto, construção, uso e manutenção das edificações, é pouquíssimo contemplada como disciplina no currículo das escolas de engenharia e arquitetura no País. Portanto, são raros os profissionais que consideram esse fator ao projetar uma edificação. Assim, esse requisito passa a ser tratado somente como um item de atendimento compulsório/burocrático à regulamentação do Corpo de Bombeiros ou da Prefeitura local. 
A engenharia civil é considerada como base fundamental na regulamentação, fiscalização e implementação de dispositivos para segurança das edificações. Para execução do projeto a construtora deve ir junto ao órgão municipal (secretária de obras), e apresentar todos os projetos e documentação de regulamentação necessárias, a fim de obter alvará de construção civil, documento que irá autorizar o início da execução da obra. Os serviços serão planejados e realizados em conformidade com procedimentos de trabalho específicos, e a com descrição detalhada de cada tarefa, assinados por profissionais devidamente habilitado.

De acordo com Antunes (2011), há dois tipos de proteção: ativa ou passiva. Para proteção ativa, as principais medidas são:

- Sistema de detecção e de alarme de incêndio;

- Sistema de sinalização de emergência;

- Sistema de controle da fumaça de incêndio;

- Sistema de iluminação de emergência;

- Sistema de extintores de incêndio;

- Sistema "Sprinklers" ou chuveiros automáticos;

- Brigada de incêndio;

Para Brentano (2007), a proteção passiva envolve todas as formas de proteção que devem ser consideradas no projeto arquitetônico para que não haja o surgimento do fogo, por causa das atividades desenvolvidas na edificação.

Para Fagundes (2013), as principais medidas de proteção preventiva ou passiva nas edificações, são:

- Afastamento entre edificações;

- Segurança estrutural das edificações;

- Saída de emergência;

- Acesso de viatura de corpo de bombeiros junto as edificações;

- Sistema de detecção de calor;

- Controle de materiais de revestimento e acabamentos; 
- Brigada de incêndio;

Para a medida de proteção a incêndio o autor Fagundes (2013, p.21), diz que:

As principais medidas de proteção preventiva ou passiva nas edificações, são: Afastamento entre edificações; Segurança estrutural das edificações; Compartimentações horizontais e verticais; Saídas de emergência; brigada de incêndio (FAGUNDES; 2013, p. 21).

Esses cuidados são tomados no planejamento do projeto, onde será proposto a localização adequada dos equipamentos que provocam incêndios, utilizando os equipamentos de detecção de alarmes de combate ao fogo, como como sensores, detectores de fumaça e calor, entre outros.

\subsection{NORMAS E PROCEDIMENTOS TÉCNICOS}

Antes de iniciar o projeto de prevenção a construtora deve se basear nas normas e procedimentos técnicos do Código de Segurança Contra Incêndio e Pânico. As normas vigentes fornecem ferramentas para planejar e executar o sistema de abandono em caso de emergência em qualquer tipo de edificação seja ela residencial, comercial ou industrial, as principais Normas são:

- NBR 9.077 - Saídas de emergências em edifícios;

- NBR 12.693 - Sistema de Proteção por Extintores;

- NBR 13.434 - Sinalização de Segurança Contra Incêndio e Pânico;

- NBR 10.898 - Sistema de lluminação de Emergência;

- NBR 14.276 - Brigada de Incêndio;

- NBR NBR17240 - Sistemas de Detecção e Alarme de Incêndio: projeto, instalação, comissionamento e manutenção de sistemas de alarme de incêndio - Requisitos.

- NBR 6492-Representação de projetos de arquitetura;

- NR-35-Serviço para Trabalho em Altura;

A norma NR 23, estabelece critérios que os empregadores devem adotar medidas de prevenção e combate a incêndio de acordo com as normas aplicáveis. 
23.1 Todos os empregadores devem adotar medidas de prevenção de incêndios, em conformidade com a legislação estadual e as normas técnicas aplicáveis.

23.1.1 O empregador deve providenciar para todos os trabalhadores informações sobre:

a) utilização dos equipamentos de combate ao incêndio;

b) procedimentos para evacuação dos locais de trabalho com segurança;

c) dispositivos de alarme existentes.

23.2 Os locais de trabalho deverão dispor de saídas, em número suficiente e dispostas de modo que aqueles que se encontrem nesses locais possam abandoná-los com rapidez e segurança, em caso de emergência.

23.3 As aberturas, saídas e vias de passagem devem ser claramente assinaladas por meio de placas ou sinais luminosos, indicando a direção da saída.

23.4 Nenhuma saída de emergência deverá ser fechada à chave ou presa durante a jornada de trabalho.

Os projetos de segurança devem possuir símbolos e sinalizações que orientarão as pessoas em uma comunicação mais rápida de segura. No projeto deve apresentar os seguintes processos:

- Iluminação de emergência;

- Saídas de emergência, devidamente protegido e sinalizado;

- Sistemas de extintores:

- "Sprinklers" ou chuveiros automático;

- Sistema de controle de fumaça e etc.

Segundo a NBR - 10898 (1999), a iluminação de emergência deve clarear áreas escuras de passagens, horizontais e verticais, incluindo áreas de trabalho e áreas técnicas de controle de restabelecimento de serviços essências e normais, na falta de iluminação normal. 
No projeto estarão previstas as áreas de riscos e o sistema necessário para evitar o surgimento de um incêndio limitando a sua propagação, permitindo o abandono dos ocupantes e acesso dos profissionais do Corpo de Bombeiros. As medidas de segurança contra incêndio em uma edificação são necessárias e fundamentais para a prevenção e redução de ocorrências e seus danos.

\section{METODOLOGIA}

Para o desenvolvimento desse artigo, foram realizadas pesquisas bibliográficas, que possui como base livros, manuais e normas relacionados ao Sistema de Prevenção ao Incêndio, que foi expandida para um estudo de caso, onde foi acompanhado as visitas in loco, podendo ser registrados alguns procedimentos de coletas de dados e de funcionamento dos sistemas, juntando um relatório fotográfico, projetos e documentos de dimensionamento. Com base nesses dados será proposto o projeto dos serviços de melhorias na infraestrutura no Sistema de Detecção e Alarme de Incêndio em um prédio industrial de Manaus-AM.

A pesquisa caracteriza-se um método qualitativo e quantitativo, pois será proposto soluções para que a empresa se ajuste a norma devido as constantes mudanças de layout da edificação, e foi realizada a quantificação de ocorrências na edificação. Os processos metodológicos adotados foram visitas técnicas, levantamento da área de estudo, relatório fotográfico e o programa AutoCad 2018 utilizado para à adaptação da proposta de projeto para a ampliação de combate a incêndio.

\subsection{LEVANTAMENTO DA ÁREA DE ESTUDO}

O estudo de caso foi realizado em uma empresa no Polo Industrial de Manaus-AM,

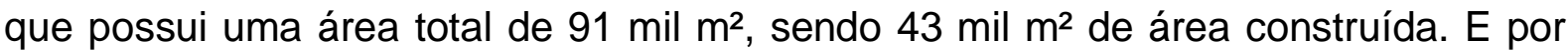
solicitação da empresa, seu nome e demais dados deverão ser suprimidos da abordagem. A empresa atualmente trabalha com fabricação de artefatos de material plástico para outros usos não especificados, que são vendidos por todo o Brasil. As visitas técnicas ocorreram durante 5 dias de segunda a sexta nos horários de 09:00 
horas as 10:00 horas, pôde-se observar e tirar fotos dos locais onde serão alterados e ampliados os sistemas de combate ao incêndio.

Os dados foram coletados através de visitas técnicas no local, apontando as principais implicações da norma de procedimentos técnicos na empresa e através de relatórios fotográficos que permitiram analisar os pontos importante, tais como, a estrutura do espaço e o estado de conservação dos equipamentos.

\subsection{PROPOSTA DE PROJETO PARA AMPLIAÇÃO DE COMBATE A INCÊNDIO}

Para entender sobre o local, fez-se necessário recorrer a planta baixa da edificação, por ser uma construção antiga, houve com o passar do tempo adequações necessárias devido as alterações do layout da empresa. Para cada instalação foi apresentada o tipo de intervenção dos serviços conforme norma NBR 17240/2010, ilustrado na figura 2.

Figura 2 - Croqui esquemático da edificação.

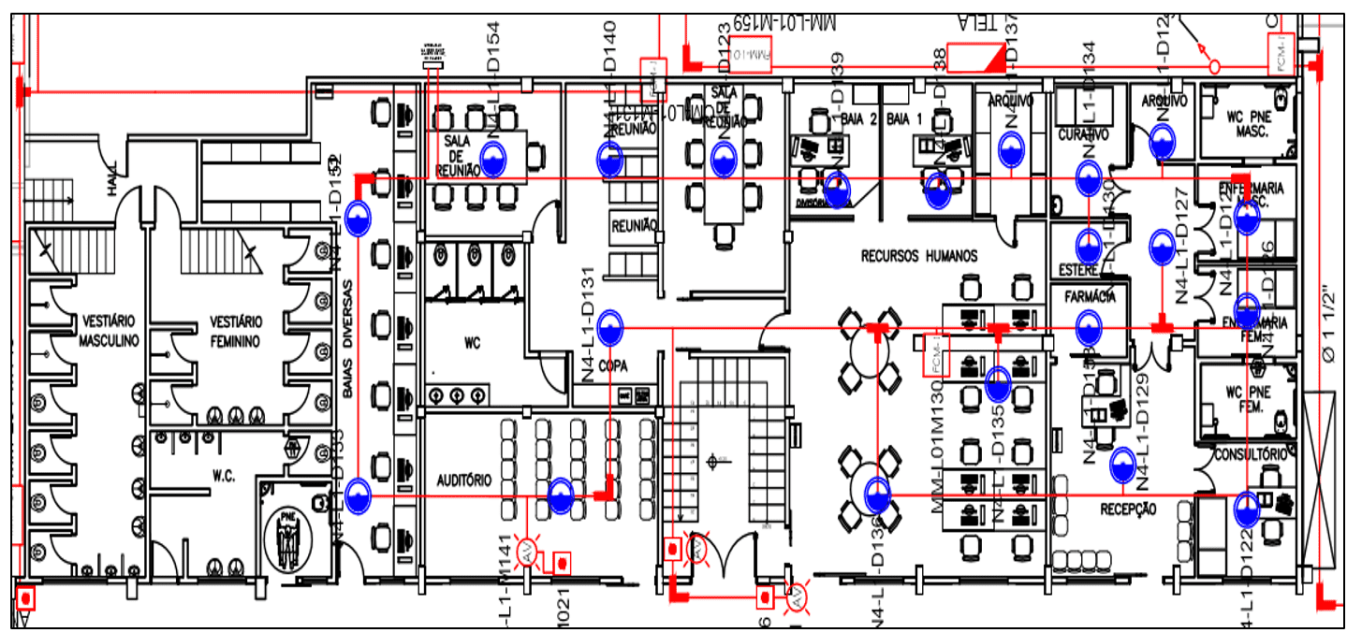

Fonte: Acervo do autor, 2019.

A proposta inclui a reorganização e descrever os Serviços de melhorias na infraestrutura no sistema de deteç̧ão e alarme de Incêndio da edificação. 


\section{RESULTADOS E DISCUSSÕES}

Após a aplicação dos procedimentos metodológicos, será possível apresentar os resultados obtidos através das visitas técnicas e do relatório fotográfico, que possibilitaram a identificação de uma relação de não conformidade, apresentadas na figura 3

Figura 3 - Relação de não conformidade encontrada.

\begin{tabular}{|c|c|c|}
\hline Item & Local & Não conformidades \\
\hline 01 & \multirow{3}{*}{$\begin{array}{l}\text { Central de Alarme Prédio C02- } \\
\text { Sala da Manutenção Injeção. }\end{array}$} & Está com a saída do SLC A+ queimada. \\
\hline 02 & & $\begin{array}{l}\text { Bornes das baterias estão oxidados e as tensões estão } \\
\text { baixas. }\end{array}$ \\
\hline 03 & & Porta de comunicação rede de fibra com defeito. \\
\hline 04 & Todas as Centrais & $\begin{array}{l}\text { Falta de organização dos cabos de alimentação elétricas, } \\
\text { SLC e fibra. }\end{array}$ \\
\hline 05 & \multirow{3}{*}{$\begin{array}{l}\text { Sistema Detecção e Alarme de } \\
\text { Incêndio. }\end{array}$} & $\begin{array}{l}\text { Não possui atualização do projeto com identificação do } \\
\text { trajeto da infraestrutura e seus cabeamentos; trajeto das } \\
\text { fibras entre os painéis, Diagrama unifilar. }\end{array}$ \\
\hline 06 & & Infraestruturas de várias padronizações (diversos). \\
\hline 07 & & $\begin{array}{l}\text { O sistema possuem vários tipos de cabos: blindado } \\
\text { trançado, PP e singelo, descaracterizando as } \\
\text { recomendações do fabricante dos equipamentos. }\end{array}$ \\
\hline
\end{tabular}

Fonte: Autoria própria, 2019.

Com base no relatório fotográfico foi detectado a necessidade da elaboração do projeto contra incêndio e pânico para a mudança de layout da empresa, fazendo com que o proprietário contrate profissionais habilitados (engenheiros civis ou arquitetos), sendo fiscalizado e aprovado pelo Corpo de Bombeiros e prefeitura. As áreas que necessitam mudanças são:

- Depósito de inflamável;

- Depósito próximo ao restaurante;

- Restaurante;

- Área de lazer;

- Ferramentaria;

- Sala de peças; 
- Torre resfriamento;

- Almoxarifado;

- Montagem;

- Hall circulação próximo refeitório;

- Casa de bomba;

Para cada ambiente foi proposto troca de equipamentos danificados e atualização dos ambientes nas plantas arquitetônicas da fábrica, que em alguns casos estavam incompatíveis com os projetos atuais da empresa.

A figura 4 mostra a infraestrutura externa que precisa de melhorias, pois a empresa está com lançamento de novos produtos no mercado e necessita se adequar as novas instalações de máquinas, por esse motivo é necessário a ampliação no sistema de detecção e alarmes contra incêndios, e aproveitando para fazer o levantamento para as manutenções necessárias.

Figura 4 - Adequações necessárias de infraestruturas.

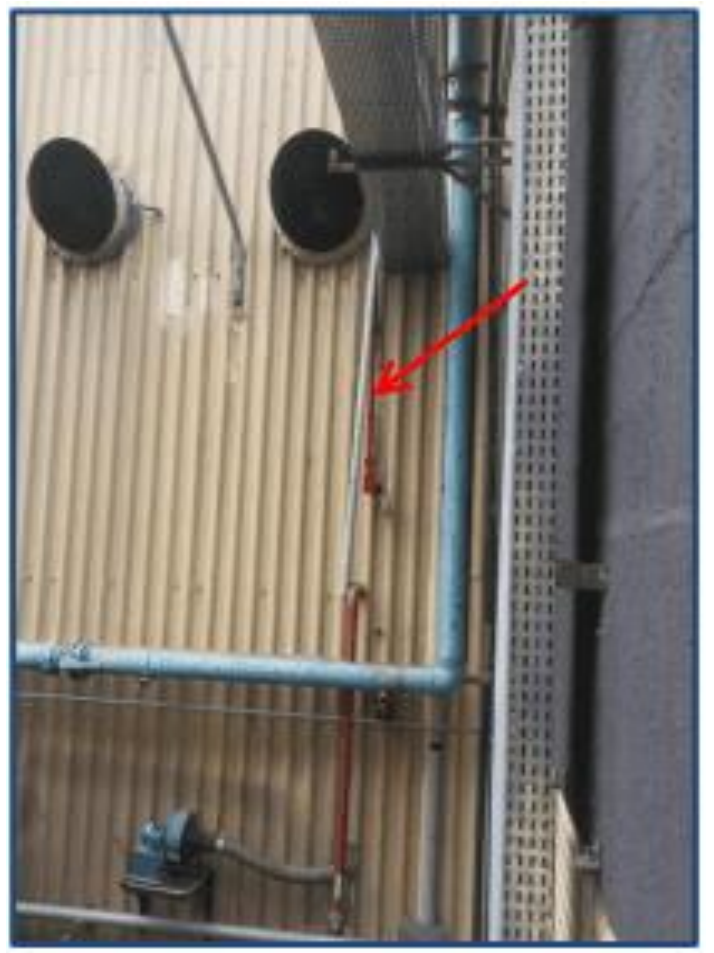

Fonte: Acervo do autor, 2019. 
Em todos esses locais relacionados na empresa será implantado os projetos de combate a incêndio, equipamentos de extinção, sinalização e iluminação de emergência. Essas adequações são necessárias e as apresentações obrigatórias em projeto foram: equipamentos de extinção, sinalização e iluminação de emergência, como pode ser ilustrado na figura 5 .

Figura 5 - Simbologia preventiva e combate a incêndio.

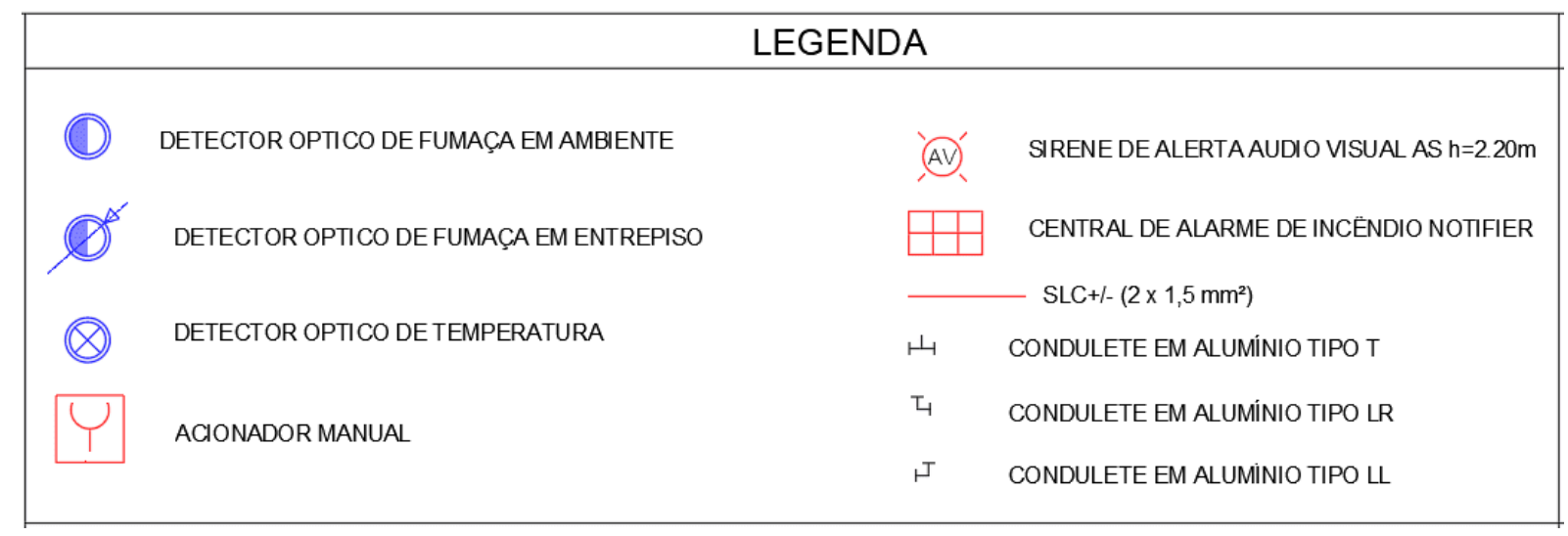

Fonte; Autoria própria, 2019.

Todos os procedimentos devem estar de acordo com as normas e com as representações de projetos de arquitetura, e em todos os locais da fábrica devem possuir placas fotoluminescentes, isto é, devem brilhar no escuro, para garantir a segurança em evacuações em casos de incêndios, ilustrado na figura 6 . 
Figura 6 - Placas fotoluminescente.
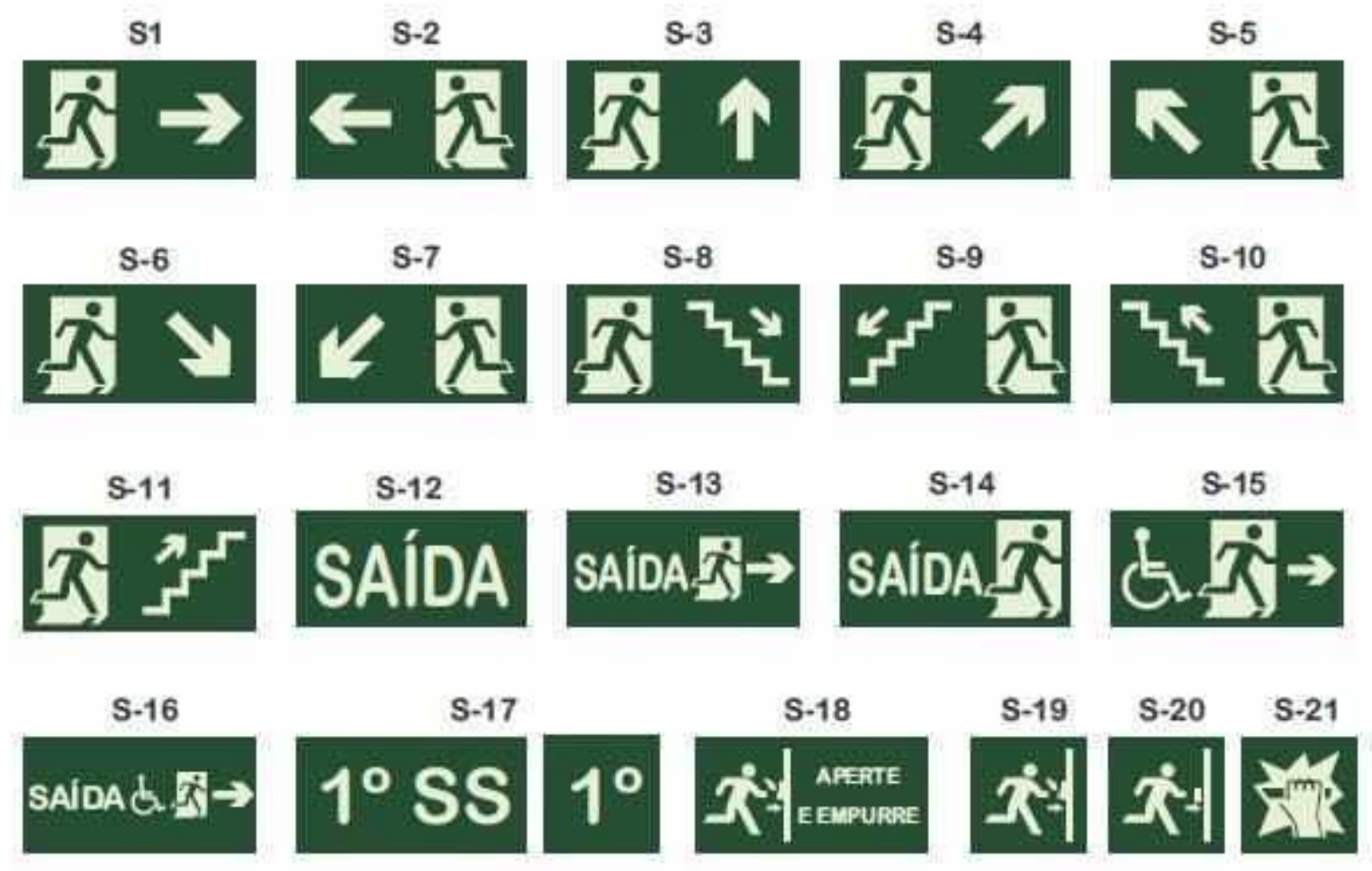

Fonte: FORTHLUX, 2019.

Pode-se constatar que fábrica está com suas fiscalizações em dias, possuindo um sistema de proteção contra incêndio por extintores bem instalado em relação ao arranjo físico e sinalizações de acordo com as normas vigentes. Apenas está passando por adequações internas e externas de novas instalações de detectores de fumaça, acionador manual, sirene áudio visual, sinalizações e extintores de incêndio, Vista do acionador manual no 34 no restaurante, que será realizada a programação e conexão, ilustrado nas figuras 7 . 
Figura 7 - Acionadores manuais.

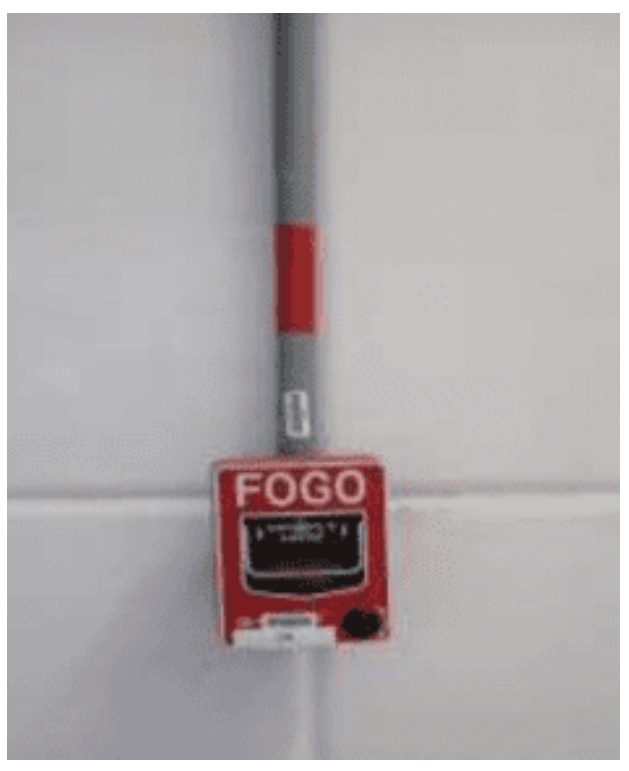

Fonte: Acervo do autor, 2019.

Durante a visita pode-se perceber que os extintores estão em quantidade e localização correta e compatível ao risco, o projeto de combate ao incêndio mostra a sinalização das sirenes e acionadores manuais na área externa do depósito de inflamáveis, conforme figura 8.

Figura 8 - Sirenes áudio visuais.

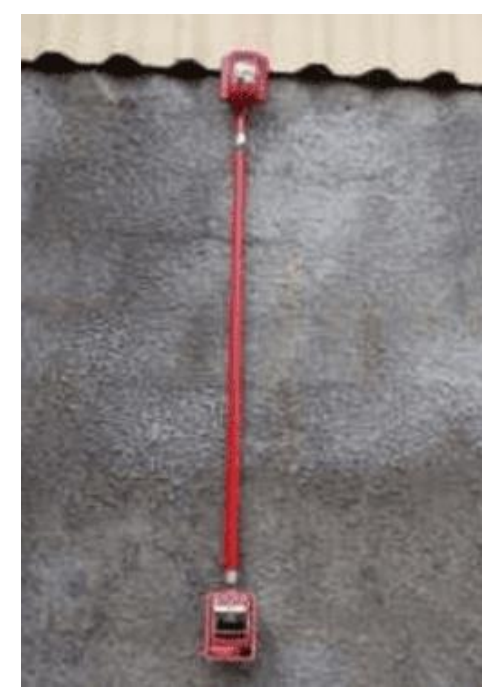

Fonte: Acervo do autor, 2019.

RC: 40330

Disponível em: https://www.nucleodoconhecimento.com.br/engenharia-civil/combate-a-incendio 
A figura 9 mostra as vistas das instalações de 12 detectores de fumaça ํㅡㄴ (47 à 58), 02 acionadores manuais № 29 e 30 e 02 (duas) sirenes áudio visuais no deposito inflamável.

Figura 9 - Instalações de detectores no deposito.

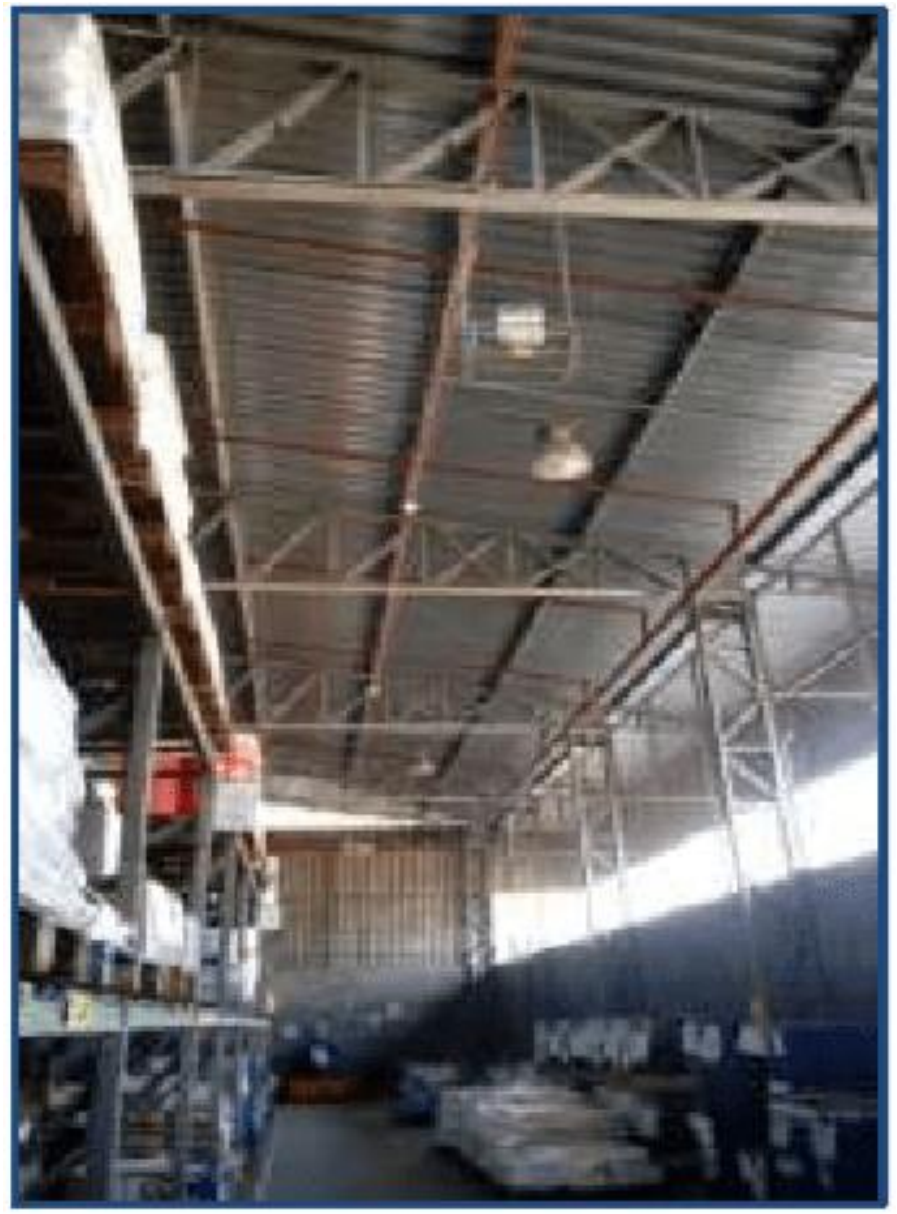

Fonte: Acervo do autor, 2019.

A proposta de Execução das melhorias na infraestrutura do sistema de detecção de alarme de incêndio de interligação do prédio:

- Será realizada instalações de eletrodutos fg pesado 1 11/2 pintado de vermelho;

- Será realizada fixação dos eletrodutos existente;

- Foi realizado o recolhimento e relançado o cabeamento do sistema de alarme;

- Será realizada substituição dos conduletes 2 1/2 quebrados; 
- Será recolhido o cabo de fibra que estava desativados na infraestrutura.

- A Interligação do detector no 19 interno do Evolution na infraestrutura existente:

- Será realizada instalações de eletrodutos fg leve 3/4 pintado de vermelho;

- Será realizado lançamento do cabeamento do sistema de alarme.

A empresa possui brigadistas de incêndio que passaram por treinamento e uma avaliação aplicada por um representante do corpo de bombeiro com as seguintes atividades:

- Instrução teórica de combate a incêndio:

- Prática de combate a incêndio:

- Instrução teórica de primeiros socorros:

- Prática de primeiros socorros:

Uma vez elaborado o Projeto de Prevenção e Combate a Incêndio e Pânico, faz-se necessário sua apresentação junto ao Corpo de Bombeiros, onde será protocolado e dado início a Análise e aprovação do Projeto. Toda vez que a empresa passar por reformas e mudanças de layout, deve-se sempre atualizar os projetos para que não haja problemas e executar as manutenções recomendadas para que o sistema esteja sempre em condições de funcionamento, garantindo assim maior segurança para os colaboradores da edificação.

\section{CONSIDERAÇÕES FINAIS}

Os principais objetivos desse estudo foi propor os procedimentos para prevenção de incêndios em uma edificação industrial, onde se baseou nas leis e normas vigentes, que orientam os engenheiro e arquitetos sobre o cuidado nos projetos técnicos e recomendam a segurança dos colaborados e da edificação, dando ênfase à importância de prevenção ao incêndio e pânico.

Com base nas visitas in loco da edificação, foi possível apresentar as normas de iluminação, sistema de detecção e alarme de incêndio, sistema de brigada, sistema de extintores entre outros. Todas essas normas correlacionam com o cuidado e 
segurança dos colaboradores e com a edificação, ressaltando que todos os sistemas de combate a incêndio devem contar com o treinamento para o preparo dos ocupantes em caso de um sinistro consigam utilizá-los.

Esse estudo apresentou algumas não conformidades encontradas nos Sistemas de Detecção e Alarme de Incêndio, podendo comprometer o sistema. Pois o mesmo não possuía atualização do projeto com identificação do trajeto da infraestrutura e seus cabeamentos, trajeto das fibras entre os painéis. Desta forma pode-se incluir todos os serviços de manutenção que estavam em desacordo na proposta de ampliação na planta industrial da empresa.

As propostas dos serviços foram realizadas conforme norma NBR 17240/2010 Sistemas de Detecção e Alarme de Incêndio. Os pontos que foram acrescentados no sistema, todos foram enumerados e programados nas suas respectivas centrais de alarme, todos estão em seu funcionamento normal. Por fim, conclui-se que a prevenção de incêndio é um conjunto de condutas que devem ser obedecidos e estar de acordo com as exigências do Corpo de Bombeiros, com todas as sinalizações, rotas de fugas e equipamentos de combate ao incêndio com o prazo de validade em dia, garantindo sua plena funcionalidade em suas instalações.

\section{REFERÊNCIAS}

ASSOCIAÇÃO BRASILEIRA DE NORMAS TÉCNICAS. NBR 12693: Sistema de proteção por extintores de incêndio. Rio de Janeiro: ABNT, 1993.

ASSOCIAÇÃO BRASILEIRA DE NORMAS TÉCNICAS. NBR 9077: Saídas de emergência em edifícios. Rio de Janeiro: ABNT, 2001.

ASSOCIAÇÃO BRASILEIRA DE NORMAS TÉCNICAS. NBR 13.434: Sinalização

de Segurança Contra Incêndio e Pânico - Parte 1: Princípios de Projetos. Rio de Janeiro: ABNT, 2001. 
ASSOCIAÇÃO BRASILEIRA DE NORMAS TÉCNICAS. NBR 13.434: Sinalização de Segurança Contra Incêndio e Pânico - Parte 2: Símbolos e suas formas, dimensões e cores. Rio de Janeiro: ABNT, 2004.

ASSOCIAÇÃO BRASILEIRA DE NORMAS TÉCNICAS. NBR 10.898 - Sistema de lluminação de Emergência. Rio de Janeiro: ABNT, 1999.

ASSOCIAÇÃO BRASILEIRA DE NORMAS TÉCNICAS. NBR 14.276 - Brigada de Incêndio. Rio de Janeiro: ABNT, 2006.

ASSOCIAÇÃO BRASILEIRA DE NORMAS TÉCNICAS. NBR NBR17240 - Sistemas de Detecção e Alarme de Incêndio: projeto, instalação, comissionamento e manutenção de sistemas de alarme de incêndio - Requisitos. Rio de Janeiro: ABNT, 2010.

ASSOCIAÇÃO BRASILEIRA DE NORMAS TÉCNICAS. NBR 6492-Representação de projetos de arquitetura. Rio de Janeiro: ABNT, 1994.

BONITESE, Karina Venancio. Seguranca Contra Incendio em Edificio Habitacional de Baixo Custo Estruturado em Aço. 2007. 253 f. Dissertação (Mestrado em Construção Civil) - Universidade Federal de Minas Gerais, 2007.

BRASIL. Ministério do Trabalho e Emprego. NR 23 - Proteção Contra Incêndios. Brasília, DF, 2011. Disponivel em: $<$ http://trabalho.gov.br/images/Documentos/SST/NR/NR23.pdf>. Acesso em: 21 de Set. 2019.

BERTO, A. F. Medidas de proteção contra incêndio: aspectos fundamentais a serem considerados no projeto arquitetônico dos edifícios. 1991. 351 p. Dissertação (Mestrado) - Faculdade de Arquitetura e Urbanismo da Universidade de São Paulo, São Paulo, 1991.

BRENTANO, Telmo. A Proteção Contra Incêndio no Projeto de Edificações. $2^{\underline{a}}$ ed. Porto Alegre: EDIPUCRS, 2010. 632p. 
BRENTANO, T. Instalações hidráulicas de combate a incêndios nas edificações. 3.ed. Porto Alegre: EDIPUCRS, 2007. p.450.

CAMILLO JÚNIOR. Abel Batista. Manual de Prevenção e Combate a incêndios, 15. Ed. São Paulo; Editora Senac. São Paulo, 2013.

DREHER, Mary A. Higiene e Segurança do Trabalho. Tubarão, 2004.

EXTINGUE, Incêndio. $\quad$ Disponível em $<$ http://www.extingueincendio.com.br/classificacao-dos-extintores-de-incendio/.>. Acesso em 18 de Set. de 2019.

FAGUNDES, Fabio. Plano de prevenção e combate a incêndios: Estudo de caso em edificação residencial multipavimentada. 2013. 71 f. Monografia (Departamento de Ciências Exatas e Engenharias) Universidade Regional do Noroeste do Estado do Rio Grande do Sul, URNRS, Santa Rosa, 2013.

FORTHLUX, Comunicação Visual. Disponível em <http://forthlux.com.br/o-que-e-anorma-da-abnt-nbr-13434/>. Acesso em 18 de Set. de 2019.

MITIDIERI, Luiz Marcelo, et al. A Segurança Contra Incêndio no Brasil. São Paulo: Projeto Editora, 2008. 457 p.

NORMA REGULAMENTADORA № 23 - NR 23. Proteção Contra Incêndios. Disponível em <http://www.guiatrabalhista.com.br/legislacao/nr/nr23.htm>. Acesso em 18 de Set. de 2019.

ONO, Rosaria. Parâmetros de garantias da qualidade do projeto de segurança contra incêndio em edifícios altos. Ambiente Construído. Porto Alegre, v. 7, n. 1, p.97-113. Jan/mar. 2007.

PEREIRA, A. G.; JUNIOR, C. F. A. Ensino de ciências e matemática para o exercício das atividades de segurança contra incêndios. Revista de Gestão Integrada em Saúde do Trabalho e Meio Ambiente, São Paulo (SP), v.5, n.1, p. 1-26, jan./abr. 2010. 
PEREIRA, Áderson Guimarães; POPOVIC, Raphael Rodriguez. Tecnologia em Segurança contra Incêndio. São Paulo: LTr, 2007.

POZZOBON, C. E. Proteção contra incêndios e explosões: Técnica de prevenção e combate a sinistros. Notas de aula. Curso de Pós-Graduação em Engenharia de Segurança do Trabalho. ljuí: UNIJUI, 2007.

SEITO, A. I. et al. A segurança contra incêndio no Brasil. São Paulo: Projeto Editora, 2008. 428p.

Enviado: Outubro, 2019.

Aprovado: Outubro, 2019. 